\title{
Membrane feeding of dengue patient's blood as a substitute for direct skin feeding in studying Aedes-dengue virus interaction
}

Cheong-Huat Tan ${ }^{1,2^{*}{ }^{\dagger}}$, Pei-Sze Jeslyn Wong ${ }^{1 \dagger}$, Mei-Zhi Irene Li ${ }^{1}$, Hui-Ting Yang ${ }^{1}$, Chee-Seng Chong ${ }^{1}$, Linda K. Lee ${ }^{3}$, Shi Yuan ${ }^{1}$, Yee-Sin Leo ${ }^{3}$, Lee-Ching $\mathrm{Ng}^{1,4}$ and David C. Lye ${ }^{3}$

\begin{abstract}
Background: Understanding the interaction between Aedes vectors and dengue viruses (DENV) has significant implications in determining the transmission dynamics of dengue. The absence of an animal model and ethical concerns regarding direct feeding of mosquitoes on patients has resulted in most infection studies using blood meals spiked with laboratory-cultured DENV. Data obtained from such studies may not reflect the natural human-mosquito transmission scenario. This study explored the potential of using membrane feeding of dengue patient's blood as a substitute for direct skin feeding.
\end{abstract}

Methods: Four to six-day old female Ae. aegypti were provided the opportunity to feed via direct exposure to a patient's forearm for 15 min or via exposure to EDTA-treated blood from the same patient through an artificial membrane for $30 \mathrm{~min}$. Mosquitoes from both feeding methods were incubated inside environmental chambers. Mosquitoes were sampled at day 13 post-feeding. Midgut and salivary glands of each mosquito were dissected to determine DENV infection by RT-qPCR and viral titration, respectively.

Results: Feeding rates: Direct skin feeding assay (DSFA) consistently showed higher mosquito feeding rates (93.3-100 \%) when compared with the membrane feeding assay (MFA) (48-98.2 \%). Midgut infection: Pair-wise comparison between methods showed no significant difference in midgut infection rates between mosquitoes exposed via each method and a strong correlation was observed in midgut infection rates for both feeding methods $(r=0.89, P<0.0001)$. Overall midgut viral titers $(n=20)$ obtained by both methods were comparable $(P \geq 0.06)$. Salivary gland infection: Pair-wise comparison between both methods revealed no significant difference in salivary gland infection rate. Strong correlation in salivary gland infection was observed between DSFA and MFA ( $r=0.81, P<0.0001)$. In general, mosquitoes fed directly on dengue patients and those on patients' blood $(n=11)$ had comparable virus titer $(P \geq 0.09)$.

Conclusion: DENV midgut and salivary gland infection rates showed good concordance between DSFA and MFA blood meal exposure methods. Freshly-obtained venous blood in EDTA from dengue patients for MFA can be used as a substitute to DSFA, especially in circumstances where bioethics approval or patient recruitment is difficult to obtain for vector competence studies. Nevertheless, mosquito numbers will need to be increased to compensate for lower feeding rate in MFA.

Keywords: Dengue, Aedes aegypti, Direct Skin Feeding Assay (DFSA), Membrane Feeding Assay (MFA), EDTA blood

\footnotetext{
*Correspondence: Tan_Cheong_Huat@nea.gov.sg

${ }^{\dagger}$ Equal contributors

${ }^{1}$ Environmental Health Institute, National Environment Agency, Singapore,

Singapore

${ }^{2}$ Faculty of Science, Monash University, Melbourne, Australia

Full list of author information is available at the end of the article
} 


\section{Background}

The natural cycle of dengue infection in Aedes spp. vectors begins when the mosquito feeds on a viremic host. Initial viral replication occurs in the midgut of the mosquito, followed by dissemination and replication of the dengue virus in various body parts, such as fat bodies, neural ganglia and the salivary glands [1]. Once dengue viruses (DENV) have reached the salivary glands, transmission of virus to susceptible hosts may occur during subsequent blood meals. This process is important in shaping the epidemiology of dengue and is greatly affected by a myriad of viral, mosquito, host and environmental factors. Studies of mosquito-virus interactions have generated important data that enhance our understanding of the epidemiology of dengue [2].

The role of Aedes aegypti in the transmission of dengue fever was first recognized by Bancroft [3] in 1906 by feeding mosquitoes on dengue patients. This initial finding was further corroborated by Cleland and colleagues using similar methods [4,5]. More comprehensive human to mosquito transmission studies were conducted in the Philippines by Siler et al. [6] and Simmons et al. [7]. These classical human transmission studies prompted several epidemiologically important observations including (i) lifetime infection of dengue virus in mosquito vectors, (ii) infectivity of dengue patients in the late prodromal stage to Ae. aegypti, and (iii) confirmation that Ae. albopictus is also an important vector for dengue. To date, the largest and most comprehensive studies involving human volunteers were conducted by Nguyen et al. [8] in Vietnam which revealed that the majority of symptomatic, ambulatory dengue patients were important sources of infection for vectors and that DENV plasma viremia levels served as an important marker of the duration of human infectiousness to Ae. aegypti. Most importantly, the study defined serotype-specific viremia thresholds which must be reached by vaccines or drugs to prevent DENV transmission.

The value of studies based on direct feeding cannot be overemphasized as they reflect epidemiologic reality. However, the challenges in conducting such studies limit the approach. First, ethical approval may be difficult to obtain in some countries, and secondly recruitment of patients may be a challenge. Due to these limitations and the lack of a systematically viremic animal model for DENV, studies of dengue infection in vectors have largely been restricted to membrane feeding assay (MFA) using artificial infectious blood meals [2]. These usually involve feeding mosquitoes with vertebrate blood spiked with cell cultured virus, using a device, such as a "double-jacketed" glass cylinder [9] or a Hemotek membrane feeding system (Discovery Workshops, United Kingdom) [10]. However, these methods may not accurately mimic that of the natural setting as a much higher amount of virus is required to infect mosquitoes when using artificial methods compared with feeding directly on viremic hosts [11]. Earlier studies have also shown that infection rates were lower in mosquitoes that were infected with other viruses via artificial methods compared to those feeding directly on viremic hosts $[12,13]$. These lower infection rates may be explained by the use of virus stock that had been frozen and thawed, or phenotypic virus adaptation due to numerous passages in cell culture [14-16].

In this study, we evaluated the use of membrane feeding of dengue patient's blood as a substitute for direct skin feeding in Aedes-dengue virus interaction studies. The advantages and disadvantages of membrane feeding assay and direct skin feeding assay (DFSA) are discussed.

\section{Methods}

Patient recruitment and characterisation of viremia Patients

Written informed consent was obtained from each patient. The inclusion criteria were: (i) adult, $\geq 21$ years of age, (ii) $\leq 5$ days of fever, and (iii) positive for DENV by point-of-care dengue NS1 Ag rapid test kit (Standard Diagnostic Inc, Korea). All patients were recruited from Tan Tock Seng Hospital, Singapore. Upon enrolment, $12 \mathrm{ml}$ of blood were drawn from dengue patients by a trained phlebotomist into a sterile EDTA Vacutainer ${ }^{\circ}$ tube (Beckton Dickinson, USA). The mosquitoes were then exposed to the EDTA blood within 10 min after the blood was withdrawn. All experimental procedures were conducted at the Environmental Health Institute (EHI), Singapore. The study was approved by the Domain Specific Review Board, National Healthcare Group, Singapore (NHG DSRB Ref: 2013/00111). The study was conducted from July to December 2013.

\section{DENV serum viremia levels}

DENV RNA was isolated from patient serum using the QIAamp Viral Mini Kit (Qiagen, Germany) following the manufacturer's recommendations. The number of RNA copies in patient's serum was measured using a TaqMan ${ }^{\circ}$ one-step qRT-PCR assay targeting a highly conserved 3' UTR region of DENVs. Oligonucleotide sequences used were DENVF2: 5' - AAACAGCATATTGACGCTGGGA3' and DENVR3: 5'-GGCGYTCTGTGCCTGGAWTGA TG-3', with a probe sequence of $5^{\prime}$-FAM- AGACCAGA GATCCTGCTGTCTC-MGB-3'. PCR reactions were carried out using the TaqMan ${ }^{\circledR}$ Fast Virus 1-step Master Mix (Life Technologies, USA). The one-step qRT-PCR reactions were performed in a $20 \mu \mathrm{l}$ reaction volume containing $5 \mu \mathrm{l}$ of the extracted RNA, $1 \times$ master mix, and $0.5 \mu \mathrm{M}$ each of the forward and reverse primers and $0.25 \mu \mathrm{M}$ of the probe. Amplification was performed using the RotorGene Q (Qiagen, Germany) according to the following 
programmes: one cycle each of $50{ }^{\circ} \mathrm{C}$ for $6 \mathrm{~min}$ and $95{ }^{\circ} \mathrm{C}$ for $20 \mathrm{~s}$, followed by 45 cycles each of $95{ }^{\circ} \mathrm{C}$ for $3 \mathrm{~s}$ and $60{ }^{\circ} \mathrm{C}$ for $30 \mathrm{~s}$. Amplification of the target gene from each individual patient was compared against a standard curve generated from 10-fold serial dilutions of an in-vitro transcribed dengue RNA standard.

\section{Dengue serotypes}

Dengue serotype from each patient was determined using a semi-nested PCR assay according to Lanciotti et al. [17] with modifications. Briefly, the first round of amplification reaction (dengue virus consensus primers D1 and D2), was performed using the one-step Access Quick ${ }^{\text {Th }}$ RT-PCR System (Promega, USA) following the manufacturer's recommendation with annealing temperature of $55^{\circ} \mathrm{C}$. The product of this first reaction was then used as the template for the second amplification reaction using the upstream consensus primer D1 and serotype specific primers TS1, TS2, TS3 and TS4. The second nest reaction was performed using the GoTaq $^{\circ}$ Flexi DNA Polymerase (Promega, USA) following the manufacturer's recommendation with the annealing temperature set at $55^{\circ} \mathrm{C}$. The nest 2 amplicons were analysed by agarose gel electrophoresis, stained with GelRed (Biotium, USA) and observed using UV transilluminator.

\section{Human to mosquito transmission experiments Mosquitoes}

Aedes aegypti used for the experimental infections were derived from larvae collected from residential premises during routine inspections by enforcement officers of the National Environment Agency (NEA), Singapore. Only larvae collected from geographical locations with no dengue or chikungunya transmission were used. Larvae were reared in $25 \mathrm{~cm} \times 30 \mathrm{~cm} \times 9 \mathrm{~cm}$ enamel pans containing $800 \mathrm{~mL}$ of water and fed with Plecomin ${ }^{\oplus}$ fish food (Tetra, Germany). Pupae were placed in $30 \mathrm{~cm} \times$ $30 \mathrm{~cm} \times 30 \mathrm{~cm}(\mathrm{H} \times \mathrm{W} \times \mathrm{L})$ cages before emergence into adults Adults were allowed to emerge and were maintained under standard insectary conditions at $27 \pm 1{ }^{\circ} \mathrm{C}$ and $75-80 \%$ relative humidity $(\mathrm{RH})$, with a photoperiod of $12 \mathrm{~h}: 12 \mathrm{~h}$ light:dark (L:D) cycles. $\mathrm{F}_{0}$ mosquitoes were allowed to mate randomly and fed with pathogen-free pig's blood (A*STAR Biological Resource Center, Singapore) using a Hemotek membrane feeding system (Discovery Workshops, United Kingdom) with mouse skin as membrane. The temperature of the feeding device was set to $37^{\circ} \mathrm{C}$. $\mathrm{F}_{1}$ eggs were hatched in aged water. Larvae were reared and pupae were allowed to emerge as mentioned above. This process was repeated until an $\mathrm{F}_{3}$ generation was obtained. The $\mathrm{F}_{3}$ adults were used in the feeding experiments.

To ensure mosquitoes used in the study were not harbouring specific human mosquito-borne pathogens, at least $300 \mathrm{~F}_{2}$ parental lines were pooled into groups of 10-15 mosquitoes and screened for dengue virus, chikungunya virus [18], Zika virus [19], Ross River virus [20] and Pan-Flavi RT-PCR assays [21].

\section{Direct skin feeding method}

Seventeen to 34 mosquitoes (4-6 days old) were transferred into paper cups covered with net and were starved for at least $24 \mathrm{~h}$ before exposure to dengue patients. After the EDTA blood was collected, the cup was placed on patient's forearm and the mosquitoes were exposed to feed through the net for $15 \mathrm{~min}$. As an additional precaution against escapees, all direct skin feeding experiments were performed inside a glove-box, measuring $120 \mathrm{~cm} \times 120 \mathrm{~cm} \times 240 \mathrm{~cm}$. The glove box was made of $0.5 \mathrm{~cm}$ thick acrylic plastic with three $60 \mathrm{~cm}$ diameter portholes where the patient and researcher's arm were inserted (Additional file 1: Figure S1). The opening of the portholes was covered by elastic stockinet.

After exposure, the cups containing mosquitoes were immediately placed in double-layer containers and transported to the EHI arthropod containment level 2 (ACL-2) facility. Mosquitoes were cold anesthetized by placing the cups in ice and fully engorged females were transferred to new paper cups covered with net. Engorged females were maintained in an environmental chamber (Sanyo, Japan) set at a cyclical temperature between 29 and $31{ }^{\circ} \mathrm{C}$ and $70-80 \%$ RH with a 12 h:12 h L:D cycle and provided with $10 \%$ sugar/vitamin B complex ad libitum. The conditions provided in the environmental chamber simulate that of indoor conditions in Singapore (determined by placing data loggers inside naturally ventilated living rooms of eight homes randomly distributed across the island; data not shown).

\section{Membrane-feeding method}

Fifty to 60 mosquitoes (4-6 days old) from the same colony as above were transferred to $0.5 \mathrm{~L}$ cylindrical cardboard containers and were starved for at least $24 \mathrm{~h}$ before being exposed to dengue patient blood. EDTA tubes containing blood from dengue patients were placed inside a plastic container with armoured beads (Life Technologies, USA), pre-warmed to $37{ }^{\circ} \mathrm{C}$, and immediately brought into the EHI ACL-2 facility where the blood was transferred into a Hemotek blood reservoir unit. Mosquitoes were then fed at a constant temperature of $37^{\circ} \mathrm{C}$ using the Hemotek blood feeding system with mouse skin as membrane inside a feeding chamber acting as a secondary containment. After thirty minutes of exposure to patient's blood, mosquitoes were cold anesthetized. Fully engorged females were transferred to paper cups covered with net and maintained as described above. This was carried out in tandem with DFSA. 


\section{Processing of mosquitoes}

Mosquito sampling

Up to 12 fully-engorged mosquitoes from each of the cohorts (MFA/DSFA) were sampled at day 13 post- feeding. Mosquitoes were knocked down on ice and midguts and salivary glands of each mosquito were dissected using the Medium 199 (Life Technologies, USA) and homogenized using a MM200 mixer mill (Retsch, Germany).

\section{Detection of DENV in mosquito midguts using a qRT-PCR assay}

Total RNA was amplified from mosquito midguts using the QIAamp Viral Mini Kit (Qiagen, Germany) following manufacturer's recommendations. The number of RNA copies in mosquito midguts was estimated using the same TaqMan ${ }^{\curvearrowleft}$ one-step qRT-PCR assay.

\section{Titration of DENV in mosquito salivary glands}

Viral titers in mosquito salivary glands were determined using a Vero cell-based Tissue Culture Infectious Dose50 $\left(\mathrm{TCID}_{50}\right)$ assay as described by Higgs et al. [22]. Briefly, samples were titrated in 10-fold serial dilutions in a 96well microtititer plate and incubated with Vero cells at $37{ }^{\circ} \mathrm{C}$ and $5 \% \mathrm{CO}_{2}$. After a 7-day incubation, cells were fixed and stained with a monoclonal mouse anti-DENV $(1+2+3+4)$ specific antibody (Immunology Consultants Laboaratory Inc, USA) and Vectastain ABC kit (Vector Laboratories, USA) following manufacturer's protocol. All virus titers were expressed as $\log _{10} \mathrm{TCID}_{50} / \mathrm{ml}$.

\section{Statistical analysis}

Feeding rates were calculated by dividing the number of mosquitoes that were fully engorged by the total number of mosquitoes exposed. The differences in the feeding rates between DSFA and MFA were analysed using paired Fisher's exact tests. The midgut infection and salivary gland dissemination rates were calculated by dividing the number of infected midguts or salivary glands by the total number of organs analysed. Differences in midgut and salivary gland infection rates were also compared using paired Fisher's exact tests. KolmogorovSmirnov tests indicated that the data did not conform to conditions of normality, hence non-parametric analyses were performed. The relationship of midgut and salivary glands infection rates between direct skin feeding and membrane feeding methods were analysed using the Spearman correlation coefficient tests. Differences in midgut viral genome copies and salivary gland viral titre between the two feeding methods were analysed using Mann-Whitney $U$-tests. All statistical tests were performed using MedCalc for Windows (MedCalc software, Belgium), with probability values of $<0.05$ considered significant.

\section{Results}

Patients

A total of 26 dengue patients were recruited for the study. However, one patient requested that skin feeding be stopped halfway, due to discomfort, resulting in only partial or no blood meal in a majority of mosquitoes and exclusion from the study. Of the remaining patients, 20 (80\%) were found to be infected with DENV1 , three (12\%) were infected with DENV-3, and two (8 \%) with DENV-2 (Table 1 ). The viremia level (DENV Log10 RNA copies $/ \mathrm{ml}$ ) of patients ranged from 4.75 to 9.41 (DENV-1), 3.73 to 5.6 (DENV-2) and 3.69 to 8.69 (DENV-3).

\section{Feeding rates}

Overall, DSFA consistently resulted in higher mosquito feeding rates when compared to membrane feeding (Table 1). In 11 out of 25 feeding events, a significantly higher number of mosquitoes was found to be fully engorged when they fed directly on a patient's arm as compared to those fed on the EDTA blood through a membrane $(P \leq 0.05)$. Direct skin feeding consistently achieved more than $90 \%$ feeding rates, while the rate for membrane feeding were between 48.2 and $98.2 \%$.

\section{Human to mosquito transmission Midgut infection}

All feeding experiments, regardless of the feeding method and patient viremia levels, resulted in at least one infected mosquito (Table 1). Pairwise comparisons between DSFA and MFA from each patient revealed no significant differences in midgut infection rates (Table 1). Strong correlation in midgut infection rates was observed between DSFA and MFA $(r=0.89, P<0.0001)$. Strong correlations between midgut infection rates and patient serum viremia was also observed for both DSFA $(r=0.72, \quad P<0.0001)$ and MFA $(r=0.84, \quad P<0.0001)$ (Fig. 1a, b).

The midgut viral genome copies from mossquitoes fed directly on dengue patients and those that were artificially fed with the patient's EDTA blood are shown in Fig. 2a. Overall, midgut viral titres obtained by both methods were comparable except for mosquitoes fed on patients 8 and $16(P=0.02)$. Higher midgut viral genome copies were observed in mosquitoes fed directly on patient 8, while the opposite was observed for mosquitoes fed on patient 16's EDTA blood. A small number of mosquitoes (up to three) fed on patients 1, 2 and 10, were infected (Fig. 2a). Thus, they were not included in the statistical analysis.

\section{Salivary gland infection}

Pairwise comparison between DSFA and MFA of each patient revealed no significant differences in salivary 
Table 1 Patient dengue virus (DENV) viraemia, serotype and midgut/salivary gland infection rates and virus titre in Aedes aegypti exposed using either direct skin feeding assay (DSFA) on patients or membrane feeding assay using EDTA-treated patient blood (MFA)

\begin{tabular}{|c|c|c|c|c|c|c|c|c|c|c|c|}
\hline \multirow[t]{2}{*}{ Patient } & \multirow[t]{2}{*}{ Serotype } & \multirow{2}{*}{$\begin{array}{l}\text { Serum virus titre } \\
\left(\log _{10} \text { RNAcopy/ml) }\right.\end{array}$} & \multirow{2}{*}{$\begin{array}{l}\text { Mode of } \\
\text { infection }\end{array}$} & \multirow{2}{*}{$\begin{array}{l}\text { Feeding } \\
\text { rate fed } / n \\
(\%)\end{array}$} & \multirow[t]{2}{*}{$P$-value ${ }^{a}$} & \multicolumn{3}{|l|}{ Midgut } & \multicolumn{3}{|l|}{ Salivary Glands } \\
\hline & & & & & & $\begin{array}{l}\text { Infected } / n \\
(\% \text { infection) })^{\mathrm{b}}\end{array}$ & Number of RNA copies & $P$-value ${ }^{a}$ & $\begin{array}{l}\text { infected } / n \\
(\% \text { infection })^{b}\end{array}$ & $\begin{array}{l}\text { DENV SG Titer } \\
\left(\log _{10} \mathrm{TCID}_{50} / \mathrm{ml}\right)\end{array}$ & $P$-value ${ }^{a}$ \\
\hline \multirow[t]{2}{*}{5} & 1 & 9.49 & DSFA & $30 / 30(100)$ & $<0.0001^{*}$ & $100(12)$ & $9.07 \pm 0.26$ & 0.95 & $12 / 12(100)$ & $4.98 \pm 1.03$ & 0.16 \\
\hline & & & MFA & $37 / 56(66)$ & & $100(12)$ & $9.11 \pm 0.13$ & & $12 / 12(100)$ & $5.52 \pm 0.66$ & \\
\hline \multirow[t]{2}{*}{8} & 1 & 9.21 & DSFA & $30 / 30(100)$ & $<0.0001^{*}$ & 9/9 (100) & $9.16 \pm 0.09$ & $0.02^{*}$ & $9 / 9(100)$ & $4.67 \pm 0.94$ & $0.02^{*}$ \\
\hline & & & MFA & $27 / 56(48.2)$ & & $12 / 12(100)$ & $8.45 \pm 0.54$ & & $12 / 12(100)$ & $5.24 \pm 0.28$ & \\
\hline \multirow[t]{2}{*}{9} & 1 & 5.65 & DSFA & 27/30 (90) & $0.03^{*}$ & $12 / 12(100)$ & $3.62 \pm 1.93$ & 0.88 & $0 / 12$ & 0 & ND \\
\hline & & & MFA & $38 / 56(67.8)$ & & $8 / 12(66.7)$ & $4.57 \pm 3.10$ & & $0 / 12$ & 0 & \\
\hline \multirow[t]{2}{*}{10} & 1 & 4.76 & DSFA & $30 / 30(100)$ & $0.007^{*}$ & $2 / 12(16.7)$ & 3.52 & ND & $0 / 12$ & 0 & ND \\
\hline & & & MFA & $45 / 56(80.4)$ & & 2/12 (16.7) & 3.08 & & $0 / 12$ & 0 & \\
\hline \multirow[t]{2}{*}{11} & 1 & 7.51 & DSFA & 29/30 (96.7) & 0.25 & $12 / 12(100)$ & $6.22 \pm 2.96$ & 0.52 & $6 / 12(50)$ & $3.95 \pm 0.7$ & 0.09 \\
\hline & & & MFA & $49 / 56(87.5)$ & & $12 / 12(100)$ & $6.38 \pm 3.3$ & & $5 / 12(42)$ & $4.95 \pm 0.76$ & \\
\hline \multirow[t]{2}{*}{12} & 1 & 9.18 & DSFA & 28/30 (93.3) & 1 & $12 / 12(100)$ & $9.8 \pm 0.48$ & 0.52 & $12 / 12(100)$ & $5.18 \pm 0.49$ & 0.003 \\
\hline & & & MFA & $51 / 56(91.1)$ & & $12 / 12(100)$ & $9.66 \pm 0.31$ & & $8 / 12(67)$ & $4.74 \pm 1.66$ & \\
\hline \multirow[t]{2}{*}{13} & 1 & 8.44 & DSFA & $17 / 17(100)$ & 0.57 & $12 / 12(100)$ & $9.69 \pm 0.37$ & 0.06 & $11 / 12(92)$ & $3.52 \pm 1.19$ & 0.82 \\
\hline & & & MFA & $43 / 47(91.5)$ & & 12/12 (100) & $9.73 \pm 1.51$ & & 12/12 (100) & $4.89 \pm-.66$ & \\
\hline \multirow[t]{2}{*}{14} & 1 & 5.71 & DSFA & $17 / 17(100)$ & $0.001^{*}$ & $7 / 12$ (58.3) & $3.25 \pm 1.12$ & 1 & $0 / 12$ & 0 & ND \\
\hline & & & MFA & $27 / 46(58.7)$ & & $8 / 12(66.7)$ & $2.83 \pm 0.2$ & & $0 / 12$ & 0 & \\
\hline \multirow[t]{2}{*}{15} & 1 & 5.64 & DSFA & 16/17 (94.1) & 0.66 & 11/11 (100) & $5.21 \pm 3.00$ & 0.14 & $3 / 12(27)$ & $4.19 \pm 0.57$ & ND \\
\hline & & & MFA & $37 / 42(88.1)$ & & 9/12 (75) & $3.87 \pm 2.01$ & & 1/11 (9) & 3.95 & \\
\hline \multirow[t]{2}{*}{16} & 1 & 8.85 & DSFA & $17 / 17(100)$ & 1 & $12 / 12(100)$ & $9.50 \pm 0.11$ & $0.02^{*}$ & $12 / 12(100)$ & $4.64 \pm 0.49$ & 0.8 \\
\hline & & & MFA & $46 / 46(100)$ & & $12 / 12(100)$ & $9.66 \pm 0.17$ & & 12/12 (100) & $4.34 \pm 0.67$ & \\
\hline \multirow[t]{2}{*}{17} & 1 & 4.75 & DSFA & $17 / 17(100)$ & $0.02^{*}$ & $8 / 12(66.7)$ & $2.62 \pm 0.01$ & 0.16 & $0 / 12$ & 0 & ND \\
\hline & & & MFA & 40/56 (71.4) & & $7 / 12(58.3)$ & $3.48 \pm 0.82$ & & $0 / 12$ & 0 & \\
\hline \multirow[t]{2}{*}{18} & 1 & 7.55 & DSFA & 17/17 (100) & $0.03^{*}$ & 12/12 (100) & $7.6 \pm 3.68$ & 0.06 & 1/12 (8) & 4.95 & ND \\
\hline & & & MFA & $42 / 56(75)$ & & $12 / 12(100)$ & $5.44 \pm 3.29$ & & $6 / 12(50)$ & $3.73 \pm 0.30$ & \\
\hline \multirow[t]{2}{*}{19} & 1 & 7.31 & DSFA & $17 / 17(100)$ & $0.02^{*}$ & 10/12 (83.3) & $5.9 \pm 3.26$ & 0.45 & $5 / 12(45)$ & $4.69 \pm 0.74$ & 0.76 \\
\hline & & & MFA & $39 / 54(72.2)$ & & 10/11 (90.9) & $6.89 \pm 3.17$ & & $3 / 12(25)$ & $4.52 \pm 1.00$ & \\
\hline \multirow[t]{2}{*}{20} & 1 & 8.2 & DSFA & $17 / 17(100)$ & 0.32 & $12 / 12(100)$ & $9.66 \pm 0.24$ & 0.15 & $12 / 12(100)$ & $4.25 \pm 0.49$ & 0.54 \\
\hline & & & MFA & $50 / 56(89.3)$ & & $12 / 12(100)$ & $9.51 \pm 0.18$ & & $12 / 12(100)$ & $4.36 \pm 0.52$ & \\
\hline \multirow[t]{2}{*}{21} & 1 & 8.79 & DSFA & $17 / 17(100)$ & 0.19 & $12 / 12(100)$ & $8.86 \pm 0.72$ & 0.4529 & $12 / 12(100)$ & $4.22 \pm 0.41$ & 0.63 \\
\hline & & & MFA & 49/56 (87.5) & & $12 / 12(100)$ & $9.12 \pm 0.22$ & & $12 / 12(100)$ & $4.26 \pm 0.59$ & \\
\hline
\end{tabular}


Table 1 Patient dengue virus (DENV) viraemia, serotype and midgut/salivary gland infection rates and virus titre in Aedes aegypti exposed using either direct skin feeding assay (DSFA) on patients or membrane feeding assay using EDTA-treated patient blood (MFA) (Continued)

\begin{tabular}{|c|c|c|c|c|c|c|c|c|c|c|c|}
\hline \multirow[t]{2}{*}{22} & 1 & 8.84 & DSFA & $17 / 17(100)$ & $0.02^{*}$ & $12 / 12(100)$ & $9.17 \pm 0.12$ & 0.05 & $12 / 12(100)$ & $5.02 \pm 0.34$ & 0.033 \\
\hline & & & MFA & 40/56 (71.4) & & $12 / 12(100)$ & $9.37 \pm 0.27$ & & $12 / 12(100)$ & $4.52 \pm 0.65$ & \\
\hline \multirow[t]{2}{*}{23} & 1 & 9.39 & DSFA & $17 / 17(100)$ & 0.58 & $12 / 12(100)$ & $9.05 \pm 0.21$ & 0.1489 & $12 / 12(100)$ & $3.58 \pm 0.71$ & 0.42 \\
\hline & & & MFA & $51 / 56(91.1)$ & & $12 / 12(100)$ & $9.14 \pm 0.41$ & & $12 / 12(100)$ & $3.9 \pm 0.44$ & \\
\hline \multirow[t]{2}{*}{24} & 1 & 6.31 & DSFA & 17/17 (100) & 0.17 & $12 / 12(100)$ & $5.58 \pm 2.83$ & 0.8399 & $3 / 12(17)$ & $3.84 \pm 1.33$ & ND \\
\hline & & & MFA & $42 / 56(75)$ & & $12 / 12(100)$ & $6.1 \pm 2.85$ & & $6 / 12(50)$ & $4.40 \pm 0.39$ & \\
\hline \multirow[t]{2}{*}{25} & 1 & 8.12 & DSFA & 17/17 (100) & 1 & $12 / 12(100)$ & $9.26 \pm 0.46$ & 0.5637 & $12 / 12(100)$ & $4.75 \pm 0.58$ & 0.29 \\
\hline & & & MFA & $55 / 58(94.8)$ & & $12 / 12(100)$ & $9.34 \pm 0.26$ & & $12 / 12(100)$ & $4.48 \pm 0.46$ & \\
\hline \multirow[t]{2}{*}{26} & 1 & 8.03 & DSFA & $17 / 17(100)$ & 1 & $12 / 12(100)$ & $9.03 \pm 0.34$ & 0.3865 & $12 / 12(100)$ & $4.99 \pm 0.50$ & 0.4 \\
\hline & & & MFA & $55 / 56(98.2)$ & & $12 / 12(100)$ & $8.16 \pm 2.26$ & & 10/12 (83) & $5.15 \pm 0.41$ & \\
\hline \multirow[t]{2}{*}{4} & 2 & 5.6 & DSFA & 29/30 (96.7) & 1 & $7 / 12(58.3)$ & $3.46 \pm 2.34$ & 1 & 1/12(8.3) & 4.52 & ND \\
\hline & & & MFA & $55 / 56$ (98) & & $7 / 12(58.3)$ & $3.52 \pm 2.12$ & & 1/12(8.3) & 2.52 & \\
\hline \multirow[t]{2}{*}{7} & 2 & 3.73 & DSFA & 29/29 (100) & 0.09 & $11 / 12(91.7)$ & $3.04 \pm 0.52$ & 0.21 & $0 / 12$ & 0 & ND \\
\hline & & & MFA & $51 / 58(87.9)$ & & $9 / 12(75)$ & $3.42 \pm 0.65$ & & $0 / 12$ & 0 & \\
\hline \multirow[t]{2}{*}{1} & 3 & 3.69 & DSFA & $30 / 30(100)$ & 0.15 & 1/12 (8.3) & 2.47 & ND & $0 / 12$ & 0 & ND \\
\hline & & & MFA & 47/56 (83.9) & & $2 / 12(16.7)$ & 3.11 & & $0 / 12$ & 0 & \\
\hline \multirow[t]{2}{*}{2} & 3 & 3.94 & DSFA & $30 / 30(100)$ & $<0.0001^{*}$ & $3 / 12(25)$ & $1.68 \pm 0.38$ & ND & $0 / 12$ & 0 & ND \\
\hline & & & MFA & $39 / 59(69.6)$ & & $2 / 12(16.7)$ & 1.41 & & $0 / 12$ & 0 & \\
\hline \multirow[t]{2}{*}{3} & 3 & 8.69 & DSFA & $30 / 30(100)$ & $0.0001^{*}$ & $12 / 12(100)$ & $9.23 \pm 0.18$ & 0.15 & $12 / 12(100)$ & $5.22 \pm 1.26$ & 0.16 \\
\hline & & & MFA & $40 / 60(66.7)$ & & $12 / 12(100)$ & $9.34 \pm 0.18$ & & $12 / 12(100)$ & $4.54 \pm 1.14$ & \\
\hline
\end{tabular}



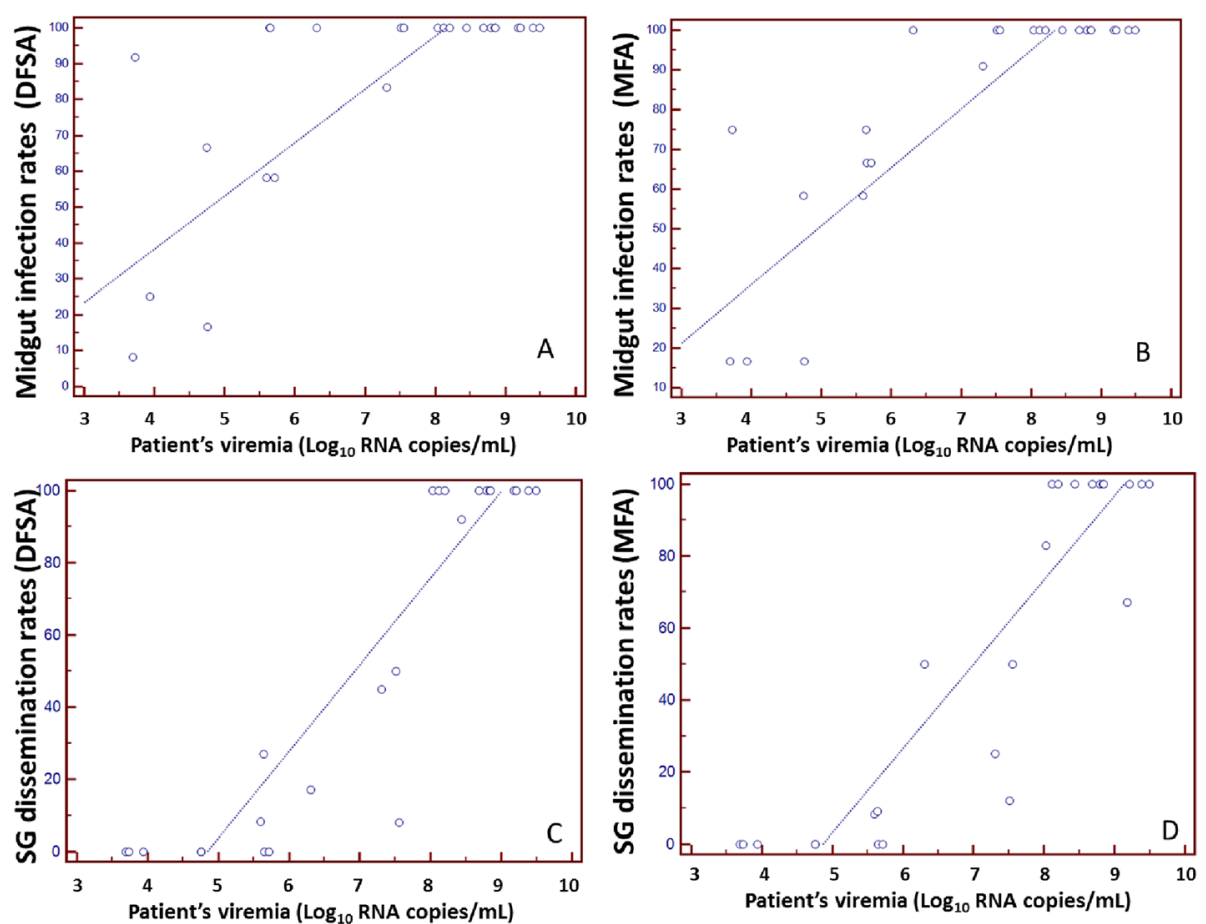

Fig. 1 Association between patient serum DENV viremia and percentage of Ae. aegypti becoming infected (midgut infection rates) and those that having disseminated infection (salivary gland infection rates) after directly feeding on 25 patients (a, c) or patient's EDTA blood fed by membrane feeding assay (MFA) (b, d). MG - midgut, SG - salivary glands

gland infection rates (Table 1). Strong correlation in salivary gland infection rates was observed between DSFA and MFA ( $r=0.81, P<0.0001)$.

A strong correlation between salivary gland infection and patient serum viremia were observed for both DSFA $(r=0.80, \quad P<0.0001)$ and MFA $(r=0.79, \quad P<0.0001)$ methods (Fig. 1c, d). Unlike midgut infection, salivary gland infection was only observed in mosquitoes fed on patients with viremia of more than $5.5 \log _{10}$ copies $/ \mathrm{ml}$ (Table 1).

The viral titres of the salivary gland of mosquitoes fed directly on dengue patients and those that were artificially fed with the patient's EDTA blood are shown in Fig. $2 \mathrm{~b}$. Of the 25 feeding events, seven did not produce disseminated infections (Patients 1, 2, 7, 9, 10, 14 and 17). Another five feeding events (Patients 4, 15, 18, 19, and 24) resulted in only up to three mosquitoes with salivary gland infection, in one or both methods. Thus, only salivary gland viral titres from the remaining 13 feeding events were analysed. Overall, the viral titre of the salivary glands from both methods were comparable, except for mosquitoes fed on Patients 8 and 22 ( $P \leq$ 0.03) (Fig. 2b). Higher salivary gland viral titres were observed in mosquitoes fed on patient 8's blood, while the opposite was observed for mosquitoes fed directly on Patient 22.

\section{Discussion}

Direct skin feeding assay is commonly used to measure human malaria infectivity to anopheline vectors and has been the method of choice in measuring the transmissionblocking activity among candidate vaccines and determining the effectiveness of anti-transmission malaria drugs $[23,24]$. Due to ethical issues involved in directly exposing human patients to mosquito bites, several studies were previously undertaken to compare the effectiveness between the DSFA and MFA in measuring the transmission potential of Plasmodium from patients to vectors [23-28]. Although DSFA mimicked the natural setting in measuring mosquito infectivity, most of these studies concluded that MFA could be used to replace DSFA in situations where direct exposure of patients to mosquito bites was not possible.

Despite the extensive use of DSFA for malaria studies, there are only a few reports on its use for studying the transmission of dengue from patients to Aedes vectors $[6-8,29]$. The absence of systemic viremic animal models to study dengue transmission has restricted all experimental oral infection of mosquitoes to those conducted artificially. The common methods of infecting Aedes mosquitoes with artificial infectious blood meal to determine the competence of these vectors have some limitations. Serial passages of flaviviruses in cell culture 

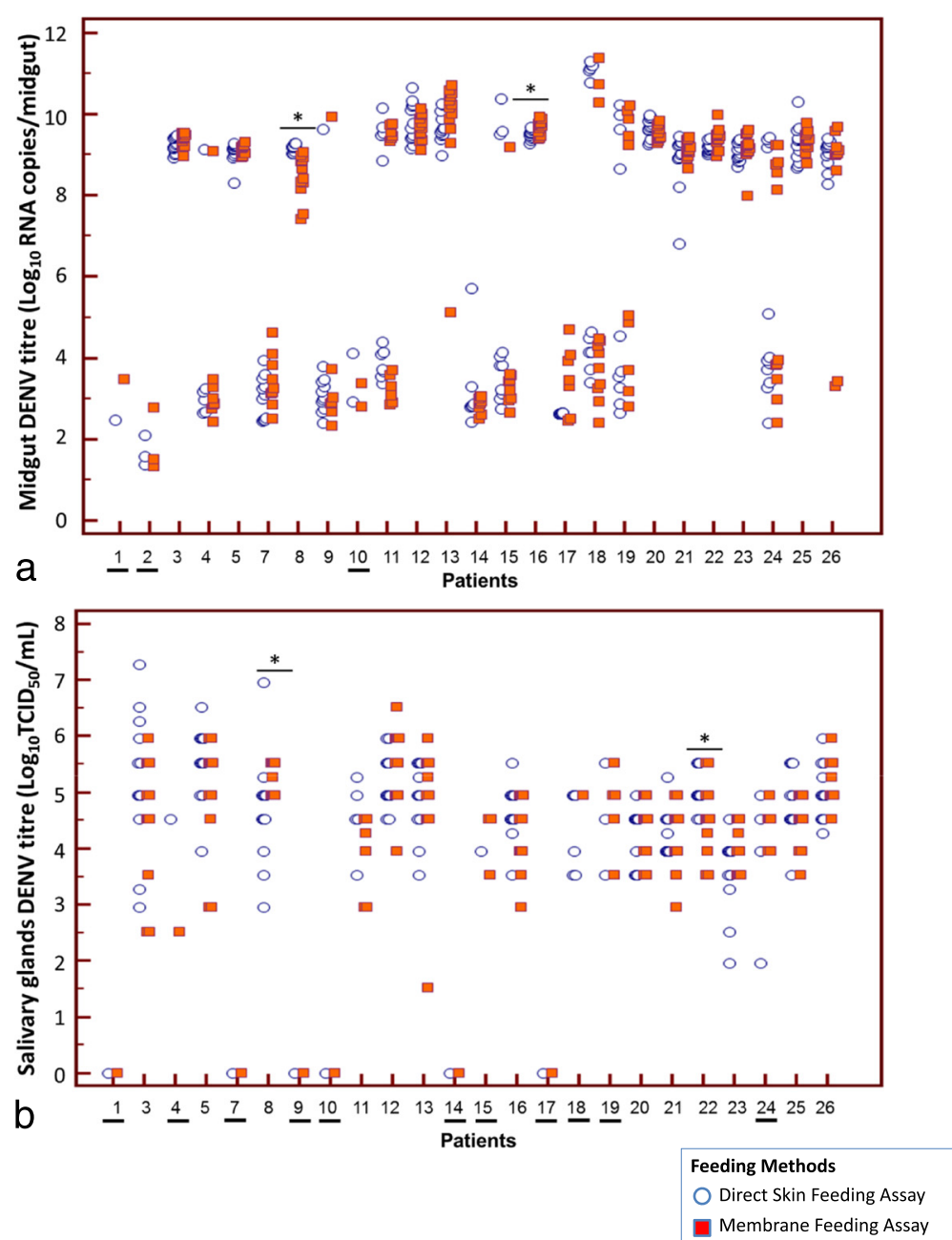

Fig. 2 a Midgut DENV titre in Ae. aegypti fed directly on patients (blue circles) and those fed patient's EDTA blood via membrane feeding assay (MFA) (red squares). Midgut DENV titre were expressed as Log10 copies/midgut. *denotes significant difference, $P<0.05$. Each point represents an individual midgut. Note: Due to small sample size, Mann-Whitney U-tests were not conducted for underlined patients' numbers (1, 2 and 10). b DENV salivary gland titre in Ae. aegypti fed directly on patients (blue circles) and those fed patient's EDTA blood (red squares). DENV titres were expressed as $\log _{10} \mathrm{TCID} 50 / \mathrm{ml}$. *denotes significant difference, $P<0.05$. Each point represents an individual salivary gland. Note: Due to absence of disseminated infection (patient no 1, 2, 7, 9, 10, 14 and 17) or small sample size (4, 15, 18, 19 and 24), Mann-Whitney U-tests were not conducted for these feeding events (underlined patients' numbers)

may select for viral mutations that may not be normally found in nature and these changes may alter viral phenotypes, such as attenuation of virulence [15, 30-32]. The viral states in a cell line and the host may also differ. Several studies have shown the adaptation and loss of virulence in DENV and other viruses when serially passaged in cell cultures [30,33-36]. It has been reported that certain modifications of DENV surface antigens occur as a result of the incorporation of cell membrane components into the virus [36]. In addition, blood from a viremic patient may contain host factors that may influence viral profiles and modulate vector competence, and these components may not be present in an artificial blood meal [2]. During the progression of illness in patients and depending on the infecting DENV serotype and previous exposure of the patient to the virus, antidengue antibodies (IgM and IgG) will continue to increase and may influence viral profiles in the patient and affect mosquito susceptibility by neutralizing DENV and preventing virus infection of the midgut [37]. These limitations highlight the need for cautious interpretation of results when performing vector competence studies using artificial blood meals or frozen-thawed samples. The use of freshly- drawn venous blood from symptomatic dengue patients for MFA could potentially avoid the disparities described above. In this study, we did not compare the mosquito infection rates between freshlydrawn venous blood and frozen-thawed blood samples. However, we assume that use of frozen-thawed blood samples from dengue viraemic patients may artificially 
lower the estimate of vector competence. A study conducted by Richards et al. [14], showed that frozen-thawed DENV has diminished infectivity in Ae. aegypti when compared to using fresh virus for the infection of mosquitoes.

The type of anticoagulants used may also affect vector competence. The use of heparinized blood lowers the infectivity of DENV4 over the feeding period, while use of defibrinated blood in vector competence studies may inhibit the attachment of virus onto the mosquito's midgut cells $[38,39]$. Although the effect of EDTA on the kinetics of DENV have not been shown, we have conducted extensive study in our laboratory to compare live animals (guinea pigs) and EDTA blood as a blood-meal source for our different mosquito colonies [40]. We have found no difference in terms of survival rates of females, their fecundity, and hatching rates across eight generations. At present, EDTA is routinely used as anticoagulant for blood feeding of our mosquitoes and for our infection work. In our current study, the overall DENV midgut and salivary gland infection results at 13 days post- infection showed good concordance between the two methods, suggesting that MFA using freshly- drawn blood treated with EDTA closely mimicked direct skin feeding.

This study compared exposure of mosquitoes using fresh blood via MFA with DSFA. The main advantage of DSFA is that it consistently showed higher feeding rates (90 to $100 \%$ ) when compared to the MFA (48.2 to $98.2 \%)$. This could reflect the strong preference of $A e$. aegypti to feed on humans. However, the lower feeding rate obtained through MFA can be compensated by increasing the number of mosquitoes used. MFA offers the advantage of potentially higher rate of patient recruitment for such studies and can be performed on residual blood drawn for diagnostic tests. Therefore, it is less intrusive and could reduce the potential risk of allergic reaction to mosquito bites. The advantages offered by MFA outweigh the inconvenience of having to use more mosquitoes to compensate for the reduced feeding rate in MFA. Table 2 summarizes the advantages and disadvantages of both feeding methods.

Although we observed positive correlations between host viremia levels and midgut infection/salivary gland infection rates in mosquitoes, the rates of salivary gland infection was consistently lower than the midgut infection rates. The lower number of mosquitoes with infected salivary glands than midguts may be due to the presence of a salivary gland infection barrier preventing the dissemination of the virus to these organs; however, the presence of such barriers for dengue viruses in Aedes mosquitoes is still highly debated [41]. An alternative explanation for the observed lower infection rates in salivary glands could be due to the cell-based infectivity assay used in the detection of DENV in the salivary glands instead of the more sensitive qRT-PCR assay that was used to detect midgut infection. Although a more sensitive technique, with a lower threshold of detection, dengue RNA concentrations derived from qRT-PCR assay may not directly translate into infectious virus titre in the hosts $[42,43]$. The qRT-PCR assay also measures non-infectious immature and defective virions which are not capable of further infection and replication. However, accurate measurement of infectious virus is critical to understanding dengue transmission; thus, the more laborious cell-based infectivity assay was chosen to measure infectious DENV in the most important organ for transmission, the salivary glands.

The current study was dominated by patients with DENV-1 as recruitment was conducted in 2013, when Singapore was in the midst of a DENV-1 outbreak. Hence, most of the patients enrolled in the study were infected with DENV-1 (80 \%), the remainder were infected with DENV-2 (8 \%) and DENV-3 (12\%). None of the patients enrolled in the study were found to be infected with DENV-4 which is not common in Singapore [44]. Another drawback of the study is the limited number of patients recruited. Despite our best effort to recruit dengue

Table 2 Advantages and disadvantages between Direct Skin Feeding Assay (DSFA) and Membrane Feeding Assay (MFA)

\begin{tabular}{|c|c|c|}
\hline & DSFA & MFA \\
\hline Advantages & $\begin{array}{l}\text { - Closely resembles natural feeding } \\
\text { - No delay between obtaining patient blood } \\
\text { sample and and mosquito feeding } \\
\text { - Prevents needle-stick injury } \\
\text { - Higher mosquito feeding rates }\end{array}$ & $\begin{array}{l}\text { - Most diagnostic assay require venous blood } \\
\text { - Patient more likely to give consent } \\
\text { - Fewer ethical considerations/constraints } \\
\text { - Allows sampling from wider age-range group } \\
\text { (including children) } \\
\text { - Allows using large number of mosquitoes and/or } \\
\text { different species of mosquitoes } \\
\text { - Allows manipulation of viral titre }\end{array}$ \\
\hline Disadvantages & $\begin{array}{l}\text { - Patient less likely to provide consent } \\
\text { - Ethical approval required (difficult or impossible } \\
\text { to obtain in some countries) } \\
\text { - Exclusion of children based on ethical considerations } \\
\text { - Potential exposure of patients to other arboviruses } \\
\text { - Risk of experiments being terminated during } \\
\text { feeding due to patient's discomfort }\end{array}$ & $\begin{array}{l}\text { - Delay between sampling and mosquito feeding } \\
\text { - Potential exposure of phlebotomist to blood-borne } \\
\text { pathogens (needle-stick injury) } \\
\text { - Need for patient to undergo needle penetration } \\
\text { (potentially aversive in some cases) } \\
\text { - Low mosquito feeding rates }\end{array}$ \\
\hline
\end{tabular}


patients, we managed to recruit 26 individuals willing to provide venous blood and allowed themselves to be bitten by mosquitoes. This is in stark contrast to the study conducted by Nguyen et al. [8] whereby large numbers of patients (>100) agreed to take part in Vietnam.

\section{Conclusion}

To our knowledge, this may be the first report comparing DSFA and MFA using patient venous EDTA blood to infect $A e$. aegypti with dengue viruses. Our results showed that freshly- obtained venous blood from symptomatic dengue patients for MFA can be effectively used as a substitute for DSFA, with no compromise in midgut and salivary gland infection rates or titres, especially in circumstances where bioethics approval or patient recruitment are difficult to obtain for vector competence studies.

\section{Additional file}

Additional file 1: Figure S1. Patient's arm inside a glove-box during

feeding experiments. (DOCX $25 \mathrm{~kb}$ )

\section{Competing interests}

The authors declare that they have no competing interests.

\section{Authors' contributions}

Conceived and designed the experiments: CHT, LCN, DL. Recruitment of patients: DL, LYS, LL. Performed the experiments: CHT, PSJW, MZIL, HTY. Analysed the data: CHT, CCS, SY. Wrote the manuscript: CHT, LCN. All authors read and approved the final version of the manuscript.

\section{Acknowledgement}

We thank Mr. Derek Ho, Director-General for Public Health, National Environment Agency (NEA) for his support on the study. We would also like to thank all patients for participating in the study. We are grateful to Diana Tan and Monica Laus for facilitating patient recruitment/phlebotomy. We thank Prof. Scott O'Neill (Monash University, Melbourne, Australia) and colleague Dr. Chanditha Hapuarachchi for their critical review of the manuscript. The study was financially supported by The National Environment Agency and the STOP Dengue Translational Clinical Research programme, funded by the National Research Foundation through the National Medical Research Council, Singapore (NMRC/TCR/005/2008). The funder had no role in study design, data collection and analysis, decision to publish, or preparation of the manuscript.

\section{Author details \\ ${ }^{1}$ Environmental Health Institute, National Environment Agency, Singapore, Singapore. ${ }^{2}$ Faculty of Science, Monash University, Melbourne, Australia. ${ }^{3}$ Communicable Disease Center, Tan Tock Seng Hospital, Singapore, Singapore. ${ }^{4}$ School of Biological Sciences (SBS), Nanyang Technological University, Singapore, Singapore.}

Received: 18 March 2015 Accepted: 23 March 2016 Published online: 15 April 2016

\section{References}

1. Kramer LD, Ebel GD. Dynamics of flavivirus infection in mosquitoes. Adv Virus Res. 2003;60:187-232.

2. Lambrechts $L$, Failloux $A B$. Vector biology prospects in dengue research. Mem Inst Oswaldo Cruz. 2013;107(8):1080-2.

3. Bancroft TL. On the etiology of dengue fever. The Australasian Med Gaz. 1906;25:17.

4. Cleland JB, Bradley B, McDonald W. Further experiments in the etiology of dengue fever. J of Hyg. 1919;18(3):217-54.
5. Cleland JB, Bradley B, McDonald W. Dengue fever in Australia. J Hyg. 1918; 16(4):319-418.

6. Siler JE, Hall MW, Hitchens AP. Dengue: its history, epidemiology, mechanism of transmission, etiology, clinical manifestations, immunity and prevention. Philippine J Sci. 1926;29:1-302.

7. Simmons JS, St John JH, Reynolds FHK. Experimental studies of dengue. Philippine J Sci. 1931;44:1-247

8. Nguyet MN, Duong TH, Trung VT, Nguyen TH, Tran CN, Long VT, Dui le T, Nguyen HL, Farrar JJ, Holmes EC et al. Host and viral features of human dengue cases shape the population of infected and infectious Aedes aegypti mosquitoes. Proc Natl Acad Sci U S A. 2013;110(22):9072-7.

9. Rutledge LC, Ward RA, Gould DJ. Studies on the feeding response of mosquitoes to nutritive solutions in a new membrane feeder. Mosq News. 1964;24:407-19.

10. Diehlmann $\mathrm{H}$, editor. Laboratory rearing of mosquitoes using a Hemotek feeding system. Hronov: Czech Republic Grafické závody; 1999.

11. Rodhain F, Rosen L: Mosquito vectors and dengue virus-vector relationships. Dengue and dengue hemorrhagic fever. Edited by: Gubler DJ, Kuno G. 1997, Cambridge, MA: CABI Publishing. 47-60.

12. Jupp PG. The susceptibility of four South African species of Culex to West Nile and Sindbis viruses by two different infecting methods. Mosq News. 1976;36:166-73

13. Meyer RP, Hardy JL, Presser SB. Comparative vector competence of Culex tarsalis and Culex quinquefasciatus from the Coachella, Imperial, and San Joaquin Valleys of California for St. Louis encephalitis virus. Am J Trop Med Hyg. 1983;32(2):305-11.

14. Richards SL, Pesko K, Alto BW, Mores CN. Reduced infection in mosquitoes exposed to blood meals containing previously frozen flaviviruses. Virus Res. 2007:129:224-7.

15. Chen WJ, Wu HR, Chiou SS. E/NS1 modifications of dengue 2 virus after serial passages in mammalian and/or mosquito cells. Intervirology. 2003;46(5):289-95.

16. Miller BR. Increased yellow fever virus infection and dissemination rates in Aedes aegypti mosquitoes orally exposed to freshly grown virus. Trans $\mathrm{R}$ Soc Trop Med Hyg. 1987;81(6):1011-2.

17. Lanciotti RS, Calisher CH, Gubler DJ, Chang GJ, Vorndam AV. Rapid detection and typing of dengue viruses from clinical samples by using reverse transcriptase-polymerase chain reaction. J Clin Microbiol. 1992;30(3):545-51.

18. Hasebe F, Parquet MC, Pandey BD, Mathenge EG, Morita K, Balasubramaniam $V$, et al. Combined detection and genotyping of Chikungunya virus by a specific reverse transcription-polymerase chain reaction. J Med Virol. 2002;67(3):370-4.

19. Lanciotti RS, Kosoy OL, Laven JJ, Velez JO, Lambert AJ, Johnson AJ, Stanfield SM, Duffy MR. Genetic and serologic properties of Zika virus associated with an epidemic, Yap State, Micronesia, 2007. Emerg Infect Dis. 2008;14(8):1232-9.

20. Studdert MJ, Azuolas JK, Vasey JR, Hall RA, Ficorilli N, Huang JA. Polymerase chain reaction tests for the identification of Ross River, Kunjin and Murray Valley encephalitis virus infections in horses. Aust Vet J. 2003;81(1-2):76-80.

21. Moureau G, Temmam S, Gonzalez JP, Charrel RN, Grard G, de Lamballerie X. A real-time RT-PCR method for the universal detection and identification of flaviviruses. Vector Borne Zoonotic Dis. 2007;7(4):467-77.

22. Higgs S, Olson KE, Kamrud Kl, Powers AM, Beaty B. Viral expression systems and viral infection in insects. In: Beard CB, Louis C, editors. The molecular biology of insect disease vectors. London, UK: Chapman and Hall; 1997. 459 - 483.

23. Bousema T, Dinglasan RR, Morlais I, Gouagna LC, van Warmerdam T, Awono-Ambene $\mathrm{PH}$, et al. Mosquito feeding assays to determine the infectiousness of naturally infected Plasmodium falciparum gametocyte carriers. PLoS One. 2012;7(8):e42821.

24. Diallo M, Toure AM, Traore SF, Niare O, Kassambara L, Konare A, Coulibaly M, Bagayogo M, Beier JC, Sakai RK et al. Evaluation and optimization of membrane feeding compared to direct feeding as an assay for infectivity. Malar J. 2008;7:248.

25. Sattabongkot J, Maneechai N, Phunkitchar V, Eikarat N, Khuntirat B, Sirichaisinthop J, et al. Comparison of artificial membrane feeding with direct skin feeding to estimate the infectiousness of Plasmodium vivax gametocyte carriers to mosquitoes. Am J Trop Med Hyg. 2003;69(5):529-35.

26. Awono-Ambene HP, Diawara L, Robert V. Comparison of direct and membrane feeding methods to infect Anopheles arabiensis with Plasmodium falciparum. Am J Trop Med Hyg. 2001;64(1-2):32-4.

27. Bonnet S, Gouagna C, Safeukui I, Meunier JY, Boudin C. Comparison of artificial membrane feeding with direct skin feeding to estimate infectiousness of Plasmodium falciparum gametocyte carriers to mosquitoes. Trans R Soc Trop Med Hyg. 2000;94(1):103-6. 
28. Graves P, Gelband H, Garner P. The SPf66 Malaria vaccine: What is the evidence for efficacy? Parasitol Today. 1998;14(6):218-20.

29. Gubler DJ, Reed D, Rosen L, Hitchcock Jr JR. Epidemiologic, clinical, and virologic observations on dengue in the Kingdom of Tonga. Am J Trop Med Hyg. 1978;27(3):581-9.

30. Ciota AT, Lovelace AO, Ngo KA, Le AN, Maffei JG, Franke MA, Payne AF, Jones SA, Kauffman EB, Kramer LD. Cell-specific adaptation of two flaviviruses following serial passage in mosquito cell culture. Virology. 2007;357(2):165-74.

31. Halstead SB, Marchette NJ. Biologic properties of dengue viruses following serial passage in primary dog kidney cells: studies at the University of Hawaii. Am J Trop Med Hyg. 2003;69(6 Suppl):5-11.

32. Weaver SC, Brault AC, Kang W, Holland JJ. Genetic and fitness changes accompanying adaptation of an arbovirus to vertebrate and invertebrate cells. J Virol. 1999:73(5):4316-26.

33. Greene IP, Wang E, Deardoff ER, Milleron R, Domingo E, Weaver SC. Effect of alternating passage on adaptation of sindbis virus to vertebrate and invertebrate cells. J Virol. 2005;79(22):14253-60.

34. Hanley KA, Manlucua LR, Gilmoreb LE, Blaney Jr JE, Hansona CT, Murphya BR, et al. A trade-off in replication in mosquito versus mammalian systems conferred by a point mutation in the NS4B protein of dengue virus type 4 . Virology. 2003;312(1):222-32.

35. Manning JS, Collins JK. Effects of cell culture and laboratory conditions on type 2 denque virus infectivity. J Clin Microbiol. 1979;10(2):235-9.

36. Sinarachatanant $P$, Olson LC. Replication of dengue virus type 2 in Aedes albopictus cell culture. J Virol. 1973;12(2):275-83.

37. Carrington LB, Simmons CP. Human to mosquito transmission of dengue viruses. Frontiers Immunol. 2014;5:290.

38. Knox TB, Kay BH, Ryan PA. Enhanced vector competence of Aedes aegypti (Diptera: Culicidae) from the Torres Strait compared with mainland Australia for dengue 2 and 4 viruses. J Med Entomol. 2003;40(6):950-6.

39. Richards SL, Anderson SL, Yost SA. Effects of blood meal source on the reproduction of Culex pipiens quinquefasciatus (Diptera: Culicidae). J Vector Ecol. 2012;37(1):1-7.

40. Lu D, Koou SY, Png AB, Ng LC, Lam-Phua SG. A novel mosquito feeding system for routine blood-feeding of Aedes aegypti and Aedes albopictus. Trop Biomedicine. 2012;29:169-74.

41. Lambrechts L, Scott TW, Gubler DJ. Consequences of the expanding global distribution of Aedes albopictus for dengue virus transmission. PLoS Negl Trop Dis. 2010;4(5):e646.

42. Pongsiri A, Ponlawat A, Thaisomboonsuk B, Jarman RG, Scott TW, Lambrechts L. Differential susceptibility of two field Aedes aegypti populations to a low infectious dose of dengue virus. PLoS One. 2014;9(3): e92971.

43. Choy MM, Ellis BR, Ellis EM, Gubler DJ. Comparison of the mosquito inoculation technique and quantitative real time polymerase chain reaction to measure dengue virus concentration. Am J Trop Med Hyg. 2013;89(5):1001-5.

44. Lee KS, Lo S, Tan SS, Chua R, Tan LK, Xu H, Ng LC. Dengue virus surveillance in Singapore reveals high viral diversity through multiple introductions and in situ evolution. Infect Genet Evol. 2011;12(1):77-85.

\section{Submit your next manuscript to BioMed Central and we will help you at every step:}

- We accept pre-submission inquiries

- Our selector tool helps you to find the most relevant journal

- We provide round the clock customer support

- Convenient online submission

- Thorough peer review

- Inclusion in PubMed and all major indexing services

- Maximum visibility for your research

Submit your manuscript at www.biomedcentral.com/submit

) Biomed Central 